\title{
Engineering Geological Design of Underground Works for Upper Madi Hydroelectric Project
}

Prem Krishna K.C. and Krishna Kanta Panthi

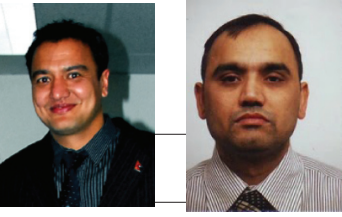

\begin{abstract}
Himalayan geology is termed as one of the youngest tectonic formations in the world. Tunneling in this region is hence complex in nature. The very complex geology in the region offers challenges in stability of even the best located underground structures. Tunneling in weak rock is more challenging in terms of stability and application of support. Moreover, in many occasion, prediction of the rock mass has been done optimistically in most of the underground projects in Nepal.
\end{abstract}

In this paper, predicted versus actual rock mass condition has been compared for two already completed projects. Based on this needed support is calculated by empirical method for the project under investigation and later on verified by numerical analysis using the software Phase ${ }^{2}$. Stability analysis is also done for both high pressure headrace tunnel and underground surge shaft. Numerical method of analysis has an added advantage over empirical and analytical methods, particularly in complex geometry. The Phase $^{2}$ code and the Hoek-Brown Failure criterion have been used to determine the state of stress, strength factor and deformations around the periphery and in the tunnel walls.

Key words: Himalayan Geology, rock mass, design of underground works, UMHEP (Upper Madi Hydroelectric Project), numerical modelling, Nepal

\section{Introduction}

Nepal has high potential for the development of hydropower projects. Only a small percentage of the total potential has been realized so far. Due to various reasons the development of the hydropower in these days is not so satisfactory. Due to political and economic reason the development of hydropower is in very slow pace and as a result the country is facing a huge power crisis these days. In topography like that of our country underground works for hydropower are essential and sometime the only option. Proper investigation and proper construction methodology are key to successful execution of any project. Beside these factors, application of support is also important for both safety and economy of the project.

The UMHEP is located in Western Development Region of Nepal (Madi Power 2000). The installed capacity of the project is $20 \mathrm{MW}$ with $126 \mathrm{~m}$ gross head and approximately $4 \mathrm{~km}$ headrace tunnel as waterway. The headwork's site is located at Chasu village and the powerhouse site is located at the bottom of Chhachwok on the right bank terrace of Madi River, a perennial snow fed river in the Gandaki River basin. The Madi River is considered to have been formed by down cutting of the valley rather than glacial action. Physiographically, the project site is located in the middle mountains, northeast of Pokhara Valley.

\section{The Himalaya in Brief}

The Himalayan Range is the highest and one of the most newly formed mountain ranges in the world. Its origin can be traced in the Jurassic Era, about 80 million years ago. The Himalayas are mainly young folded mountains. They extend across northern South Asia from west to east for about $2,500 \mathrm{~km}$ in a curve between the wide plains of the Indus and Brahmaputra rivers in the south and the vast expanse of the high Tibetan Plateau in the north (Figure 1). The main mountain range, which divides the Indian subcontinent from Nanga Parbat in the west, stretches through Kashmir and Nepal to Sikkim and Bhutan in the east. The width of the range extends from 200 to $300 \mathrm{~km}$ north-south. The Himalayas cover an area of approximately $600,000 \mathrm{~km}^{2}$.

Himalaya is one of the rare mountain ranges on the Earth where, in a single traverse, a more than $50 \mathrm{~km}$ thick vertical section of mountain can be accessed from root to top with good exposures of deep seated metamorphic rock sequences to the fossiliferous sedimentary rock on top surface. The Himalaya is considered as a tectonically very active and vulnerable mountain system. Many scientists believe that at one time the northward moving Indian plate first touched the southern edge of Tibetan (Eurasian) plate.

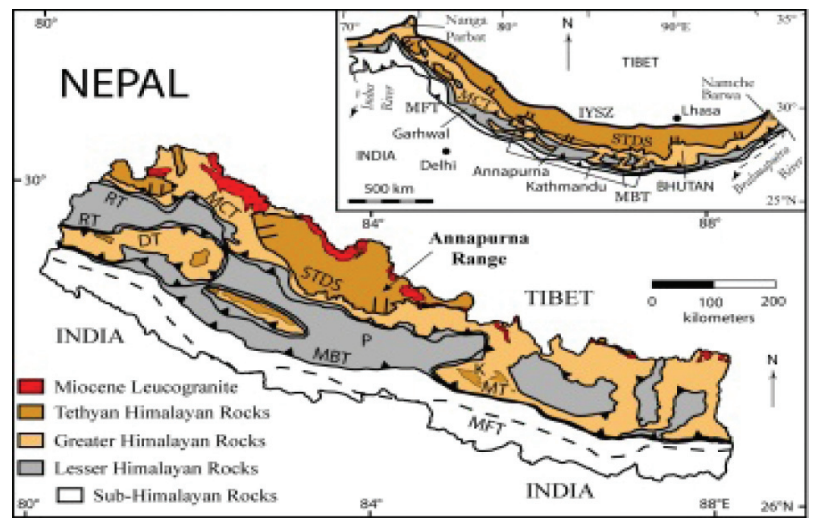

Figure 1. Geological Settings of the Himalaya Region and Nepal

\section{Geology of Project Area}

The UMHEP project area lies in the Kunchha Group of 
rocks belonging to the Lesser Himalayas of the Western Nepal. The Kunchha Group is characterized by low grade metamorphic rocks such as gritty phyllite, quartzite, phyllite, schist and intrusive rocks such as sills and dykes of amphibolites. Thus the project area is characterized mainly by meta-sedimentary rocks such as quartzite, phyllite, gritty phyllite, schist, slate, etc. (Figure 2). Quartzite, phyllite and gritty phyllite are the predominant rock types of the project area. Mica-schist and intercalation of phyllite and quartzite rock are also present at some places in the form of minor rock types. The attitude of the rock varies from place to place. The variation in the orientation of the rock is mainly due to local minor folds.

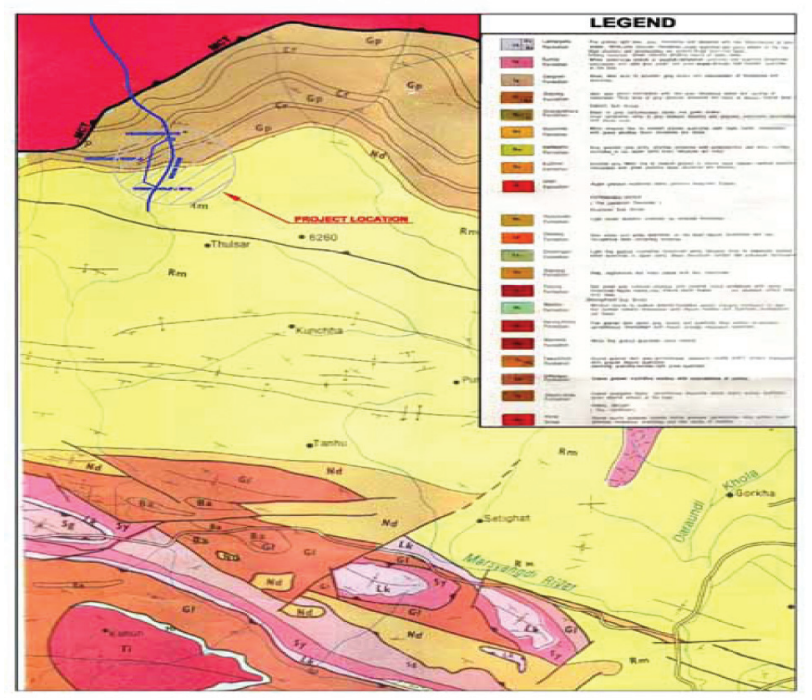

Figure 2. Regional Geology of Project Area (www.dmgnepal.gov.np)

\section{Rock Mass Classification}

Two main classifications of rock masses are widely used in case of tunnels in Nepal; i.e., Rock Mass Rating (RMR) system proposed by Bieniawski (1989) and Tunneling Quality (Q) by Barton, Lien and Lunde (1974). The same classification has been used in case of UMHEP. The details of both classifications are given in Table 1 . These two methods are used in case of Middle Marsiangdi, Khimti and Modi hydroelectric projects for the classification of quality of rock mass and estimation of rock support according to the classification.

\section{Review of Relevant Cases}

It is useful to review projects in nearby areas with similar geological condition. Since UMHEP is in the planning phase, comparison with projects already finished or implemented will be useful. Therefore, three projects, two with more or less similar geological formation and one with different geological formation, is compared with UMHEP in terms of rock mass quality classification.

\section{Middle Marshyangdi Hydroelectric Project (MMHEP)}

The MMHEP project is a run-of-river project having installed capacity 72MW, located in the Western Development Region of Nepal in Lamjung District, Gandaki Zone. It consists of $5.1 \mathrm{~km}$ of headrace tunnel and underground settling basins of size $130 \mathrm{~m}$ x 15m x 25-27m, which are first of their kind in Nepal. The surge tank is vertical $45 \mathrm{~m}$ high and $20 \mathrm{~m}$ in diameter with a concrete lining. The predicted and actual rock mass condition along the headrace tunnel is given in Figure 3.

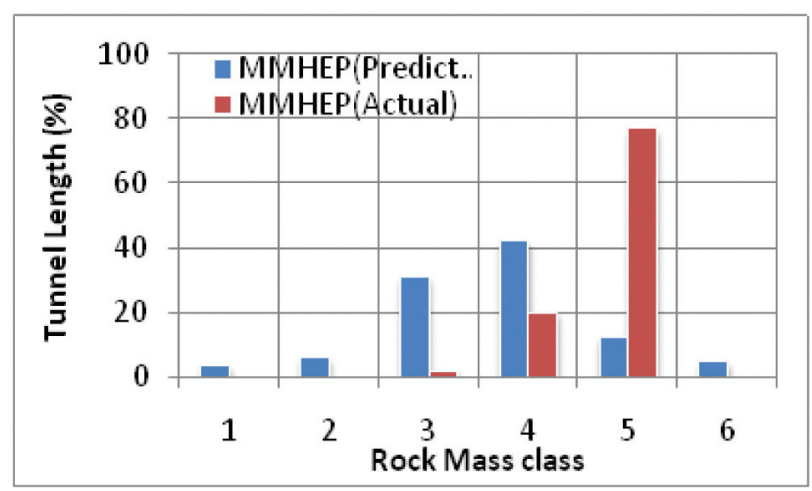

Figure 3. Predicted and Actual Rock Mass of MMHEP (Panthi and Nilsen 2007).

\section{Kali Gandaki 'A' Hydroelectric Project (KG'A'HEP)}

The Kali Gandaki 'A' HEP is a run-off-river project with $144 \mathrm{MW}$ installed capacity. It lies in western part of Nepal's Gandaki Zone in Syangja District. The major underground structures of this project are a 5910m long fully lined headrace tunnel, horse-shoe in section with $56 \mathrm{~m} 2$ cross sectional area, $26 \mathrm{~m}$ finished diameter $55 \mathrm{~m}$ high surge tank, $71 \mathrm{~m}$ high vertical shaft, $241 \mathrm{~m}$ long pressure tunnel, and a semi-underground power house. The predicted and actual rock mass conditions along the headrace tunnel are given in Figure 4. 




Figure 4. Predicted and Actual Rock Mass of Kali Gandaki 'A' Project (Panthi and Nilsen 2007).

\section{Comparisons between Cases}

Comparisons are done between rock mass quality of UMHEP with two other projects, the Middle Marshyangdi and Kali Gandaki 'A' HEPs. Comparisons are done in predicted rock mass of UMHEP with actual and predicted rock mass of MMHEP and KG'A'HEP

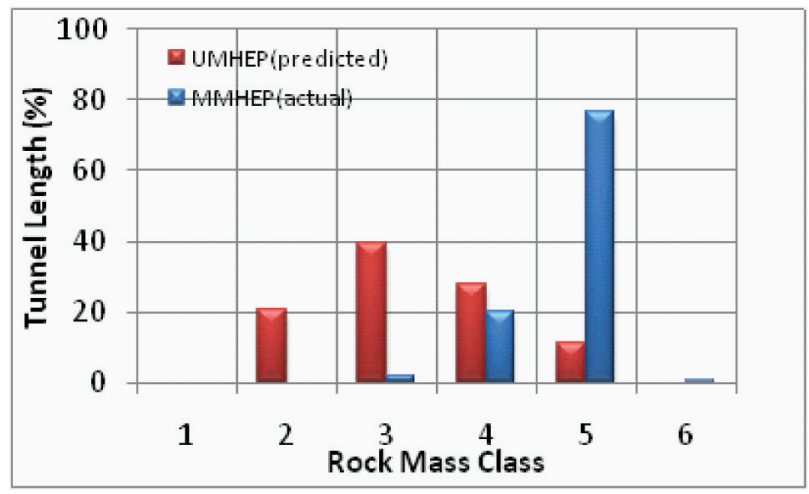

Figure 5. Comparison between MMHEP and UMHEP Rock Mass

MMHEP lies on the same geological formation as UMHEP, so the rock mass quality should in principle be very similar to that of MMHEP. Even though the rock formations in these two projects are very similar, the predicted rock mass quality along the headrace tunnel of UMHEP and actually recorded rock mass quality along the headrace tunnel of MMHEP are very different (Figure 5). The comparison between predicted rock mass quality at UMHEP with actually recorded rock mass quality at Kali Gandaki 'A' headrace tunnel also follow a similar trend (Figure 6). This indicates some degree of uncertainty in the predicted rock mass quality at UMHEP.

After comparing predicted rock mass quality with different projects with actual rock mass quality it was observed that the predicted rock mass quality is found to be different mostly with better quality rock mass. This has happened in most of the tunneling projects built in Nepal; i.e., Kali Gandaki, Khimti and MMHEP, where actual rock mass is much poorer and vary considerably in comparison to that from predicted (Panthi and

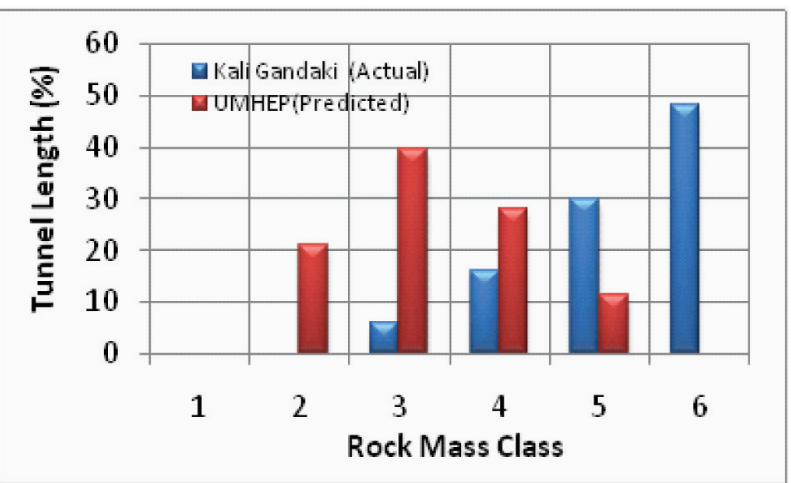

Figure 6. Comparison between Kali Gandaki and UMHEP Rock Mass

Nilsen 2007). With this view it is felt that the predicted rock mass quality at UMHEP seems very optimistic. So, an adjustment has been made for the rock mass class in UMHEP project, as shown in Figure 7.

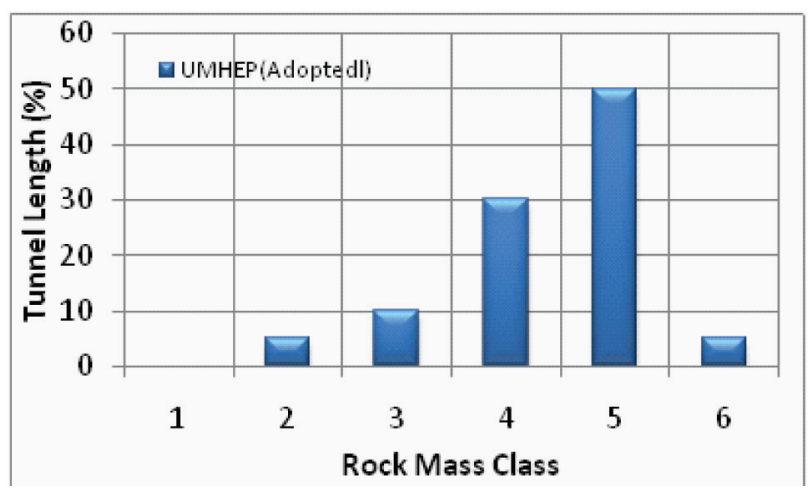

Figure 7. Adopted Rock Mass Class after Comparison with UMHEP

As indicated in Figure 7, almost $80 \%$ rock mass will have a quality class four and five; i.e., poor and very poor rock mass class according to rock mass quality in Table 1 . With the geological formation at UMHEP, the recommended quality class should represent close to real ground conditions.

\section{Numerical Modeling}

Numerical models are widely used in rock engineering; i.e., tunnels, caverns, slope stability and rock foundation works. This method is widely used due to development in analysis software and powerful computing devices. There are various numerical techniques used for analysis. Applications of empirical and analytical methods are limited to simple cases of geometry. With complexity in structural layouts and shapes and geological settings, numerical methods are widely used for assessing stress states, stability of excavations, prediction of rock failure and verification of rock support requirement.

Palmström and Nilsen (2000) define numerical modeling as discretization of the rock mass in consideration into a large number of individual elements which are analyzed by use of computers basically for the evaluation of 
rock stresses and deformations. Analytical methods imply simplified solutions like uniform loading for simple and regular shapes. Empirical methods are largely based on practical aspects and experiences, both of which have shortcomings for analyzing complex nature of rock mass. Numerical methods have few advantages that quantitative assessment can be done for stresses and deformations. Numerical models can be categorized as shown in Figure 8. A better understanding of rock mass behavior and failure mechanism becomes possible with use of parametric and sensitivity analysis.

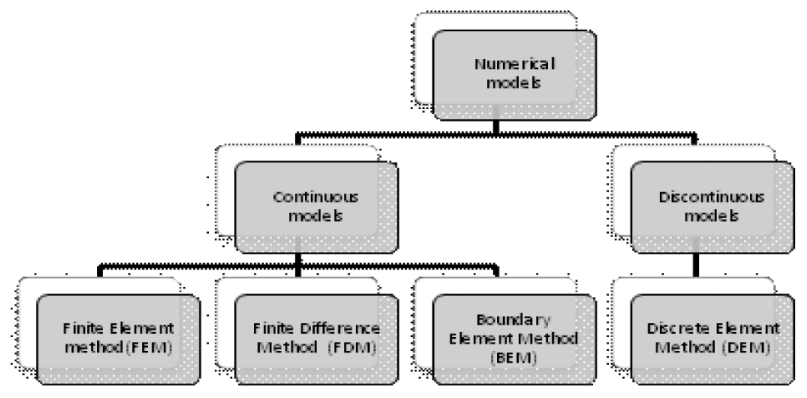

Figure 8 : General Classification of Numerical Methods (after Palmström and Nilsen 2000).

The numerical modeling method may be the tool for verification of the results determined by other methods. It is most flexible in studying the effect of changes in design and input parameters. However, restrictions and uncertainties are also connected to such modeling and obtaining reliable input parameters is one of the main uncertainties. The magnitude and directions of the virgin stresses and the properties of the in situ rock mass (e.g., sampling and scale effect) are generally the most difficult to quantify (Palmström and Nilsen 2000).

\section{The Phase 2 Program}

As defined in the Phase $^{2}$ Reference Manual (RocScience 2001a and 2001b), Phase $^{2}$ is a two dimensional finite element program for calculating stresses and displacements in underground or surface excavations. It can be used for a wide range of engineering works, including complex tunneling problems in weak rock, underground powerhouse caverns, surface excavations such as open pit mines, and slopes in rock or soil.

It has these basic application features:

- elastic or plastic materials

- staged excavations (up to 50 stages)

- multiple materials

- bolt supports

- liner support (shotcrete/concrete)

- constant or gravity field stress

- jointed rock

- plane strain or axis symmetry

- groundwater (include pore pressure in analysis)

The Phase ${ }^{2}$ program consists of three stand alone program modules:
- MODEL

- COMPUTE

\section{- INTERPRET}

MODEL is the pre-processing module used for entering and editing the model boundaries, support, in situ stresses, boundary conditions, material properties, and creating the finite element mesh.

COMPUTE is the analysis and computational module runs after completion of the numerical model to required input parameters and properties in the MODEL.

The INTERPRET module exhibits the results of the analysis for different stress conditions, deformations and yielding.

\section{Description of the Model (Tunnel)}

Three cross sections are chosen for the numerical analysis of the tunnel. These three sections represent the whole tunnel behavior in terms of rock type. The locations of section are shown in Figure 9.

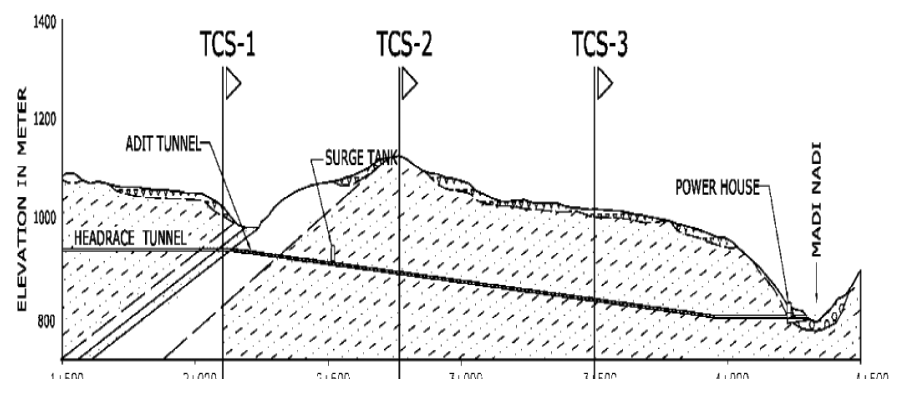

Figure 9. Tunnel Cross Section for Numerical Analysis

\section{Input Parameters}

For all three models the main rock type is phyllite. But in section 1 the tunnel lies in heavily sheared zone and for sections 2 and 3 the rock is phyllite. Material parameters and stress parameters are very important for the reliable results in numerical modeling. The input parameters used for the analysis are presented in Tables 2, 3 and 4, respectively.

\section{Phase $^{2}$ Model}

In case of tunnel, the modeling is done in three phases. The first is done only for topographic stress. The second phase is done with tunnel excavation and stress change due to this excavation. The third and final phase is tunnel support.

Topographic stress: In the topographic stress phase all the material properties and stress conditions are taken into account. This shows the tentative stress condition before the excavation of tunnel and is also used for the further analysis in tunnel support where stress condition is taken constant and stress parameter and direction are taken from this model. 
Table 2. Rock Class, Q Value and GSI Value for Different Tunnel Cross Sections (TCS)

\begin{tabular}{|c|c|c|c|}
\hline Section & Rock class & Q value & GSI value \\
\hline TCS-1 & 6 & $0.001-0.01$ & 20 \\
\hline TCS-2 & 4 & $0.1-1$ & 35 \\
\hline TCS-3 & 4 & $0.1-1$ & 35 \\
\hline
\end{tabular}

Table 3. Material Parameters for Numerical Analysis

\begin{tabular}{|c|c|c|c|}
\hline Parameter & TCS-1 & TCS-2 & TCS-3 \\
\hline Unit Weight & 0.0286 & 0.0286 & 0.0286 \\
\hline Poisson's Ratio & 0.05 & 0.05 & 0.05 \\
\hline Intact Compressive strength & $39 \mathrm{MPa}$ & $39 \mathrm{MPa}$ & $39 \mathrm{MPa}$ \\
\hline Young's Modulus & $14000 \mathrm{MPa}$ & $14000 \mathrm{MPa}$ & $14000 \mathrm{MPa}$ \\
\hline GSI & 10 & 35 & 35 \\
\hline Intact Rock Constant, mi & 7 & 7 & 7 \\
\hline Disturbance Factor, D & 0.5 & 0.5 & 0.5 \\
\hline mb parameter & 0.096 & 0.316 & 0.316 \\
\hline s parameter & $\begin{array}{c}0.00000614 \\
0.585\end{array}$ & 0.000172 & 0.000172 \\
\hline a parameter & $\begin{array}{c}\text { Generalized } \\
\text { Hoek-Brown } \\
\text { (Hoek, Carran- } \\
\text { za-Torres and } \\
\text { Corkum 2002) }\end{array}$ & & 0.515 \\
\hline & & \\
\hline
\end{tabular}

Figure 10. Phase ${ }^{2}$ Model with Tunnel Excavation

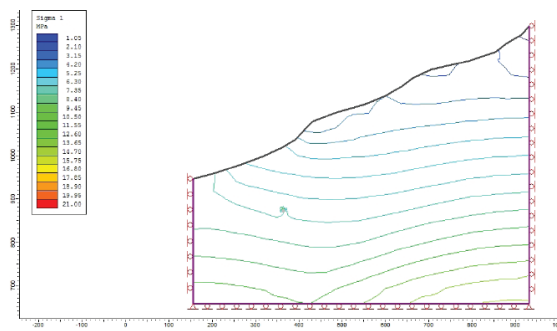

Figure 11. Stress Condition before Excavation

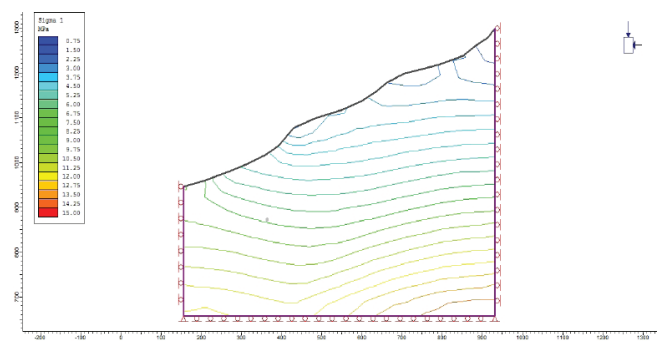

Table 4. Stress Parameters for Numerical Analysis

\begin{tabular}{|c|c|c|c|}
\hline Section & Overburden $(\mathrm{m})$ & (in plane) & (in plane) \\
\hline TCS-1 & 86.2 & 1.06 & 1.06 \\
\hline TCS-2 & 144 & 0.66 & 0.66 \\
\hline TCS-3 & 309 & 0.336 & 0.336 \\
\hline
\end{tabular}

Excavation: In the second stage of the modeling, excavation is added to topography and stress change, and various other parameters are analyzed. This is very important part of analysis and it is useful for further support analysis.

Support Analysis: In this stage analysis of tunnel support was done. There are many options available for support; i.e., shotcrete, rock bolts, steel ribs, concrete, etc., and the support calculated by analytical method is verified here. Modeling is done in restrained conditions with an external boundary five times the excavation boundary in this case. Stress condition is taken as constant and parameters are taken from topographic model as discussed earlier. Analysis is done in plastic mode and various parameters like stress condition, displacement, strength factor, yielded condition are checked in interpretation part. This is very important part in terms for the stability of tunnel and quantity of support to be applied during construction (Figure 10 to 16).



Figure 13. Change in Stress Condition after Application of Support and Yielded Support

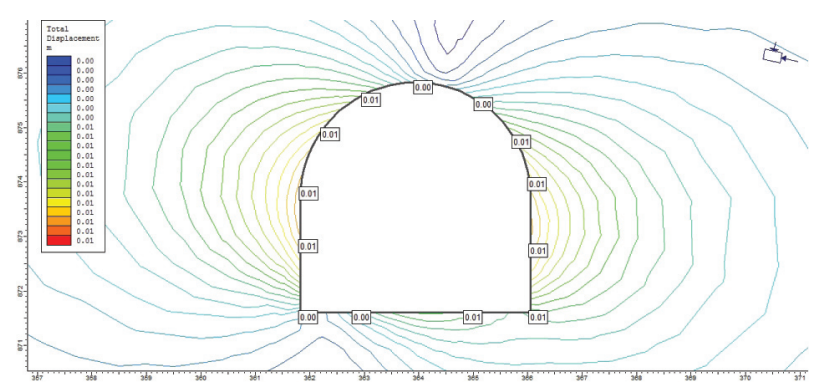

Figure 14. Change in Stress Condition after Excavation 


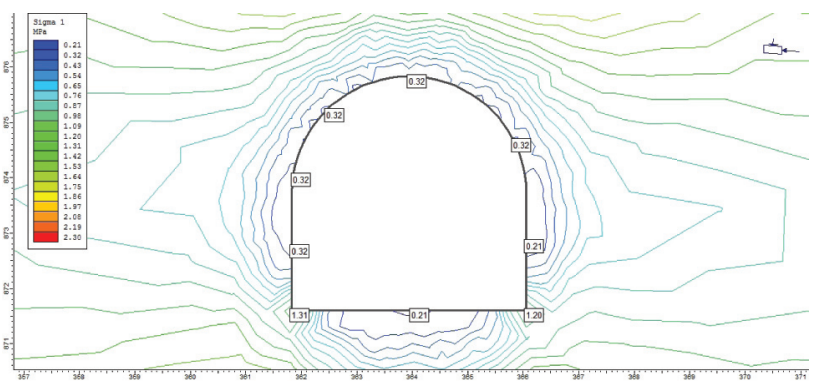

Figure 15. Displacement before Application of Support

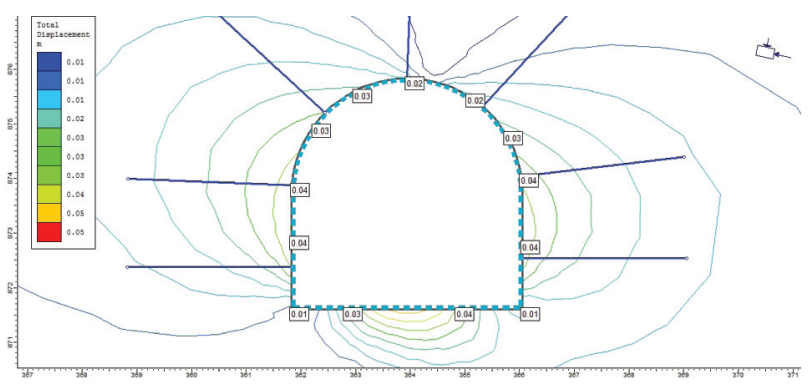

Figure 16. Displacement after Application of Support
Table 7. Details of Applied Support at Section TCS-3

\begin{tabular}{|c|l|}
\hline Support Type & Description \\
\hline Rock bolt & $\begin{array}{l}\text { Fully bonded, 25mm dia., length } 3 \mathrm{~m} @ \\
1.5 \mathrm{~m} \text { spacing }\end{array}$ \\
\hline Shotcrete & $20 \mathrm{~cm}$ thick reinforced fiber shotcrete \\
\hline
\end{tabular}

\section{Numerical Modelling of Surge Shaft}

Due to the complex geometry, modeling of surge shaft is done in stages. Altogether eight stages are used for analysis. The details of excavation and support applied on different stages are shown in Table 8.

Table 8. Excavation and support at different stages for modeling

\begin{tabular}{|c|l|}
\hline Stage & Details of work \\
\hline 1 & Excavation of dome (semi circular part) \\
\hline 2 & Application of support on dome \\
\hline 3 & Excavation of $3 \mathrm{~m}$ further by benching \\
\hline 4 & Application of support \\
\hline 5 & Excavation of remaining part of surge shaft \\
\hline 6 & Application of support \\
\hline 7 & Excavation of joining part of tunnel and surge shaft \\
\hline 8 & Application of support \\
\hline
\end{tabular}

Material parameters and stress parameters are taken same as tunnel section cross TCS-2. The optimized rock support used for the analysis is presented in Table 9 and Table 10. The Phase $^{2}$ model used is presented in Figures 17 and 18.

Table 9. Details of Applied Support in Surge Shaft Dome

\begin{tabular}{|c|l|}
\hline Support Type & Description \\
\hline Rock bolt & Fully bonded,25mm dia., length $4 \mathrm{~m} @$ \\
& $1.2 \mathrm{~m}$ spacing \\
\hline Shotcrete & $30 \mathrm{~cm}$ thick reinforced fiber shotcrete \\
\hline
\end{tabular}

Table 10. Details of Applied Support in Surge Shaft

\begin{tabular}{|c|l|}
\hline Support Type & Description \\
\hline Rock bolt & $\begin{array}{l}\text { Fully bonded,25mm dia., length } 4 \mathrm{~m} @ \\
1.2 \mathrm{~m} \text { spacing }\end{array}$ \\
\hline Shotcrete & $30 \mathrm{~cm}$ thick reinforced fiber shotcrete \\
\hline
\end{tabular}

\section{Results/Interpretation}

After modeling, interpretation option in Phase2 is used for result interpretation. The interpretation is mainly used for stress condition, displacement and strength factor before and after the application of the support at different stages as shown in Figures 19, 20, 21 and 22. The maximum principle stress values are in the crown. After the application of support it reaches the maximum value of 4.20 at crown. This is normal stress and it is increased because of the load split at stage 2 is $70 \%$.

Table 6. Details of Applied Support at Section TCS-2

\begin{tabular}{|c|l|}
\hline Support Type & Description \\
\hline Rock bolt & $\begin{array}{l}\text { Fully bonded, 25mm dia., length } 3 \mathrm{~m} @ \\
1.5 \mathrm{~m} \text { spacing }\end{array}$ \\
\hline Shotcrete & $15 \mathrm{~cm}$ thick reinforced fiber shotcrete \\
\hline
\end{tabular}




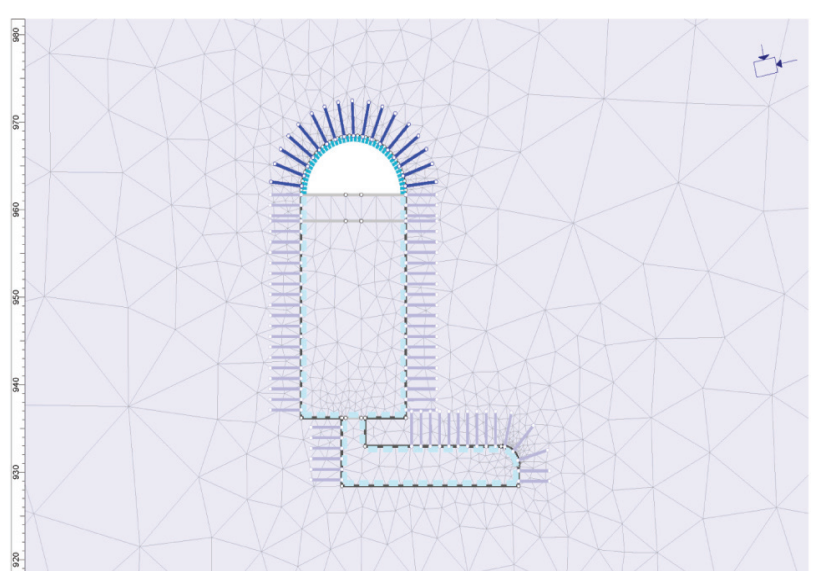

Figure 17. Excavation and Application of Support of Dome

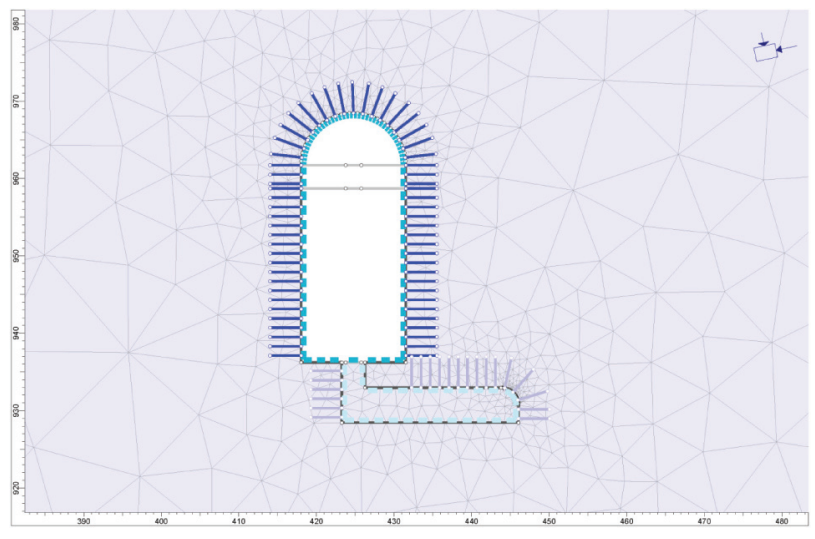

Figure 18. Excavation and Application of Support of Surge Shaft.

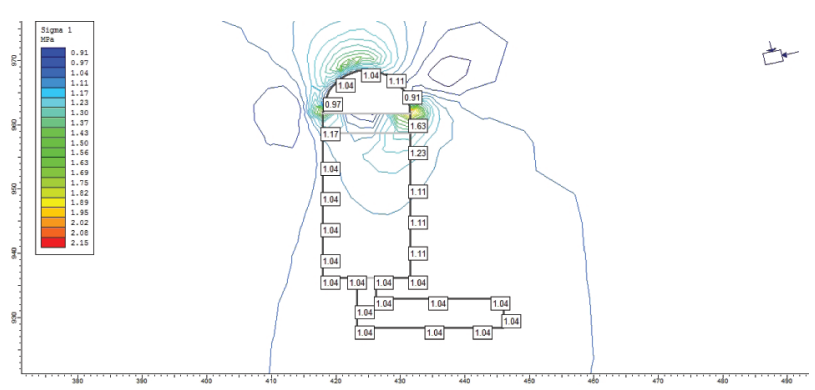

Figure 19. Change in Principal Stress after Excavation

\section{Conclusions}

The prediction of rock mass in most of the cases in Nepal is done very optimistically or it is assumed that more competent rock than actual rock mass will be encountered while excavating tunnel or other underground components. Due to the geological conditions of Nepal high uncertainty always exists in underground works. Initial geological investigations and adequate knowledge is necessary for the reliable prediction of rock mass. Rock support also plays a vital role in stability and in the cost of the underground works. Optimum use of rock support is always a big issue in most of the underground works.



Figure 20. Change in Principal Stress in Dome after Application of Support



Figure 21. Total Displacement after Application of Support in Surge Shaft

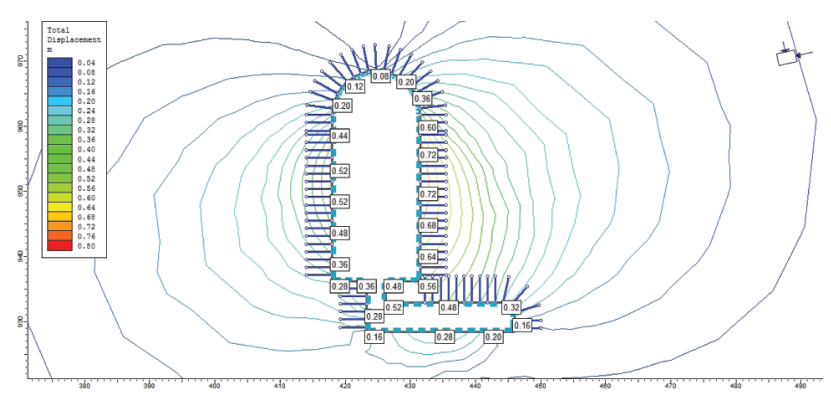

Figure 22. Total Displacement after Application of Support All Over

Conventional methods of use of rock mass classification methods like Q-method and empirical method are widely used for the prediction of rock support. Besides these methods, the numerical approach should also be used for the prediction of rock mass behavior and prediction of rock support requirement. In the program Phase2 most of the rock parameters and stress parameters are incorporated for fairly reliable analysis. Therefore, it is very useful for the estimation of rock support both for pre-construction and construction phase underground works. It is also a useful tool for stability analysis.

$$
\text { - - }
$$

Prem Krishna K.C. has a Masters degree in Hydropower Development from the Norwegian University of Science and Technology (NTNU), and six years of experience in various hydropower projects. He is currently involved in a detailed design of the Kali Gandaki Koban (4OoMW) project in Mustang District and Tamakosi-I (2OoMW) project in Dolakha District. He works as a Senior Engineer with Green Ventures, Kathmandu, Nepal. 
Corresponding Address: premkkc@gmail.com, kc@ alumni.ntnu.no

Krishna Kanta Panthi, PhD, is an Associate Professor in Geological Engineering in the Department of Geology and Mineral Resources Engineering, NTNU, Trondheim, Norway. He has completed his Dr. Ing. degree on the 'Analysis of Engineering Uncertainties Related to Tunneling in Himalayan Rock Mass Conditions' in 2006 from NTNU. He completed his MSc in Hydropower Development in 1998 and MSc in Civil Engineering in 1992. He is the author of many scientific papers related to tunneling, rock slope engineering and hydropower. He has over 15 years of experience in design, construction and planning of tunneling and hydropower projects in the Himalaya (Nepal and India).

Corresponding Address: krishna.panthi@ntnu.no

\section{References}

Barton, N., 1997, The influence of joint properties in modeling jointed rock masses, v.3, pp.1023-1032 in Proceedings of the Eighth International Congress on Rock Mechanics, Tokyo, September 1995, Rotterdam: Balkema.

Barton, N., R. Lien and J. Lunde, 1974, Engineering classification of rock masses from design of rocksupport, Rock Mechanics 6:189-236,

Bieniawaski, Z.T., 1989, Engineering Rock Mass Classifications: A Complete Manual for Engineers and Geologists in Mining, Civil, and Petroleum Engineering, Hoboken, NJ: Wiley-Interscience.

DGM (Department of Geology and Mines), 2010, URL: www.dmgnepal.gov.np.
Hoek, E., C. Carranza-Torres and B. Corkum, 2002, Hoek-Brown failure criterion (2002 edition), pp. 267-273 in R. Hammah, W. Bawden, J. Curran and M. Telesnicki (eds.), Proceedings of NARMS-TAC 2002, Mining innovation and Technology, Toronto, 10 July 2002.

K.C., Prem Krishna, 2010, Engineering Geological Evaluation of underground Works: Upper Madi Hydroelectric Project, Nepal, MSc Thesis, Norwegian University of Science and Technology (NTNU), Department of Geology and Mineral Resources Engineering, Trondheim, Norway.

Madi Power, 2000, Geological and Geotechnical Studies: Geology Report, Appendix C, Kathmandu: Madi Power Pvt. Ltd.

Palmström, A. and B. Nilsen, 2000, Engineering Geology and Rock Engineering (Handbook), Norway: Norwegian Tunnelling Society.

Panthi, K.K. and B. Nilsen, 2007, Predicted versus actual rock mass conditions: A review of four tunnel projects in Nepal Himalaya, Tunnelling and Underground Space Technology 22:173-184.

Panthi, K.K., 2006, Analysis of Engineering Geological Uncertainties Related to Tunnelling in Himalayan Rock Mass Conditions, Doctoral Dissertation, Norwegian University of Science and Technology, Norway.

RocScience, 2001a, Phase ${ }^{2}$ Programme Reference Manual, Toronto: RocScience Inc. URL: www.rocscience. com.

RocScience, 2001b, Phase ${ }^{2}$ User's Guide, Toronto: RocScience Inc. URL: www.rocscience.com.

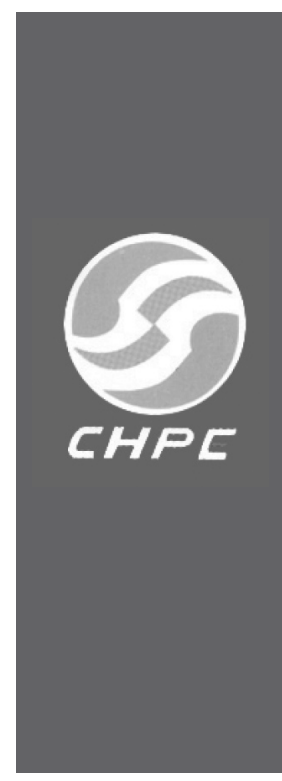

\section{Authorized Representative for Nepal Chongquing Hydropower Equipments Co. Ltd. Chongqing City, China SUPPLIER OF - Hydropower Complete Equipment - Wind Power Complete Equipment - Solar Power Equipment - Thermal Power Equipment}

ADDRESS: Patan Dhoka, Lalitpur, Tel: 977-1-5544895 (O), Fax: 977-1-5544895, Mobile: 977-1-9851035284, 9851043550

Email: ckumar.shahi@gmail.com,rakesh_lal_singh@yahoo.com 